\section{LO QUE EL TIEMPO EDUCA: EL OCIO COMO CONSTRUCCIÓN PEDAGÓGICA Y SOCIAL ${ }^{1}$}

\author{
José Antonio Caride Gómez \\ Facultad de Ciencias de la Educación \\ Universidad de Santiago de Compostela \\ Avda. Suárez Núñez, $s / n$ \\ Campus Vida. 15782 \\ Santiago de Compostela \\ joseantonio.caride@usc.es
}

\section{WHAT TIME EDUCATES; LEISURE AS A PEDAGOGIC AND SOCIAL CONSTRUCTION}

\begin{abstract}
Time is a key dimension in the construction of our signs of identity. Science has dealt with the reflections on its nature and scope since antiquity. Now its worries are accentuated, characterizing it as a plural time, constructed social and culturally. Thus, the importance of education and of the learning relative to time, which beginning in the infancy extend along the whole vital cycle. In the set of the called "social times", leisure emerges as a civic right, from which a decisive contribution is expected for the improvement of the well-being of people and of their quality of life. To educate in the values and meanings leisure offers for human development is a task in which pedagogy must actively involve. The article emphasizes the educational potential of leisure, highlighting its innovative and transforming capacity in the Network Society.
\end{abstract}

KEY WORDS: Social time; leisure; leisure education; social pedagogy; lifelong learning.

"La vida es eterna en cinco minutos"

Victor JARA (1969)

\section{INTRODUCCIÓN: EL TIEMPO COMO INQUIETUD HUMANA}

El tiempo nos hace humanos, o, al menos, así parece. En sus ritmos inscribimos una parte substancial de nuestras señas de identidad, que comienzan siendo, ellas mismas, temporales. Nacemos al tiempo y en él existimos, para que -de un modo paradójico- su vivencia nos vaya haciendo cada vez más conscientes de sus límites, por mucho que aceptemos los desafíos biológicos y sociales que se asocian a su continuo fluir. Como recuerda Giannini (2001), vivimos un tiempo determinado, que nos inquieta y asombra, sien-
RESUMEN: El tiempo es una dimensión clave en la construcción de nuestras señas de identidad. Las reflexiones sobre su naturaleza y alcance han ocupado a la ciencia desde la antigüedad. Ahora se acentúan sus preocupaciones, caracterizándolo como un tiempo plural, construido social y culturalmente. De ahí la importancia de la educación y de los aprendizajes relativos al tiempo, que iniciándose en la infancia se prolongan a lo largo de todo el ciclo vital. En el conjunto de los denominados "tiempos sociales", el ocio emerge como una necesidad y un derecho cívico, del que cabe esperar una contribución decisiva a la mejora del bienestar de las personas y de su calidad de vida. Educar en los valores y significados que aporta el ocio al desarrollo humano, es una tarea en la que la pedagogía debe comprometerse activamente. El artículo pone énfasis en el potencial educador del ocio, incidiendo en su capacidad innovadora y transformadora en la sociedad red.

PALABRAS CLAVE: Tiempos sociales; ocio; educación del ocio; pedagogía social; aprendizaje a través de la vida.

do seres en tránsito hacia un fin que no es posible eludir, y del que más pronto que tarde todas las personas acabamos tomando conciencia.

No hay vida humana sin tiempo, aunque éste pueda imaginarse más allá de nuestras particulares formas de relacionarnos con él. Sus manifestaciones lineales o cíclicas, entre cualquier antes, el ahora y un después, generan resistencias a desencontrarnos con su evolución, una vez asumida que su falta deviene en nuestro final, que es -como todo acontecimiento concreto- un hecho en el tiempo: el límite de una duración, en la que el porvenir es sustituido por el instante, que ya los griegos clásicos nombraban refiriéndose al tiempo como el "destino" de toda existencia individual. Para Gabilondo $(2008,12)$, poder interpretarlo así es un privilegio del que gozan los 
seres humanos, que no se reduce a la mera percepción de la muerte como una contrariedad: "no es un contratiempo, es cosa tanto del tiempo mismo, como de nuestra propia condición... [De modo que cuando hablamos o escribimos acerca del tiempo], en cierto sentido siempre hablamos de nosotros mismos, de lo que nos constituye y de las formas que históricamente ha adoptado esa constitución". Hace mucho, no sin fuertes discrepancias, que se intenta justificar por qué ha de entenderse así.

A tratar de aclararlo dedicaron su inteligencia reflexiva, creadora y crítica, buena parte de quienes se han interesado por dar respuesta a los enigmas del tiempo, en la Filosofía y en la Física, desde la Biología hasta la Sociología, pasando por la Psicología y la Geografía, la Antropología, la Historia, la Literatura, la Astronomía o la Matemática... porque, aun siendo en algunas de ellas un campo de investigación emergente, la "reflexión sobre el tiempo y los intentos de medirlo son tan antiguos como la propia humanidad; la huella de estos intentos se encuentra en los relatos míticos, en los calendarios y en la estructura gramatical de los idiomas" (Durán y Rogero, 2009, 11). Recordemos -entre bastantes otros- a Platón, Aristóteles, San Agustín, Galileo, Newton, Kant, Husserl, Durkheim, Proust, Mactaggart, Bergson, Halbwachs, Einstein, Merleau-Ponty, Heidegger, Ricoeur, Piaget, Zubiri, Eliade, Elias, Levinas, Merton, Braudel, Jünger, Ricoeur, Hawking... Sus obras ilustran de forma magistral cómo nuestras concepciones sobre la naturaleza y el alcance del tiempo se han ido modificando significativamente, desde la creencia en un tiempo absoluto, uniforme, lineal y objetivo hasta su progresiva percepción como un tiempo relativo, multiforme, cíclico y subjetivo. Mientras el primero -escribía Ernest Jünger (1998) en su sugerente ensayo El libro del reloj de arena, publicado en Alemania en 1957- es un poder que avanza en escalas graduadas, el segundo es un poder que retorna, que aviva el recuerdo y restituye cosas.

Situarse en el tiempo y apropiarse de él, anticipándose a un futuro incierto, forma parte de este proceso, en el que casi nada es ajeno a la educación. Acaso, porque como ha interpretado Savater (1997), por la vía de la educación, más que nacer al mundo, nacemos al tiempo y a sus registros históricos, no sólo al aprendizaje sino también a una cierta conciencia temporal. Además, porque siendo una facultad de sintesis, entre un antes y un después, el tiempo es una construcción social que debe ser aprendida e interiorizada, en la que los ritmos de la vida cotidiana son el contexto que determina dicho aprendizaje (Viñao, 1998). La pluralidad de sus trazados, en lo que Boscolo y Bertrando (1996) identifican como "los tiempos del tiempo", acentúa sus dimensiones sociales, que a diferencia de las que invoca la Física, son cualitativas: expresan "creencias, valores y costumbres propias de un grupo. Esto implica una multidimensionalidad: una multiplicidad de tiempos sociales asociados a distintos grupos y actividades, con sus propios ritmos y representaciones... de los tiempos vividos... de las diversas maneras de adaptarse a las condiciones temporales de la existencia" (Lasén, 2000, XV).

A pesar de haber aumentado nuestra posibilidad de discernir, no todos los interrogantes están resueltos. Muy al contrario, todo indica que están más abiertos que nunca a la búsqueda de nuevas respuestas; incluso a las más desconcertantes, que proponen comenzar por revisar todos los supuestos establecidos por la Física en relación con el tiempo, que afectan al movimiento y la posición de los cuerpos. Dilucidar si es una ilusión o si realmente existe, acertar con las palabras que permitan definirlo o describirlo, determinar cómo afecta nuestras vidas, desvelar simbólica y materialmente sus signos... son tareas demasiado complicadas -y complejas- como para que puedan quedar resueltas de ahora y para siempre. La definición del tiempo, concluimos con Alfonseca (2008, 169), sigue siendo "uno de los problemas más difíciles de la filosofía y de la ciencia, hasta el punto de que muchos pensadores lo soslayan, mientras que los que intentan resolverlo llegan a conclusiones muy diferentes e incluso contradictorias".

Inevitablemente, esta también ha de ser una lección (des)aprendida para transitar por la sociedad de flujos que habitamos, cuyas incongruencias, como diría el geógrafo brasileiro Milton Santos (1996, 30-31), han abonado "el terreno para el reino de la metáfora de que hoy se valen los discursos recientes sobre el Tiempo y el Espacio". Una metáfora que, en su opinión, precisamos separar teórica y empíricamente de los conceptos y de las realidades que hacen la vida más inteligible, situando el tiempo y el espacio entre las preocupaciones epistemológicas más recurrentes de la globalizada sociedad informacional. 


\section{UN TIEMPO PLURAL, CONSTRUIDO SOCIAL Y CULTURALMENTE}

El tiempo como historia, no sólo como hacedor de la Historia, vuelve a estar en el centro de los debates intelectuales que insisten en la urgencia de cambiar la mirada, renovando palabras y conceptos que presentan una creciente fragilidad, entre los que -como advierte Albert Jacquard $(1994,7)-$, el tiempo es uno de los más inestables y mutables; tanto como para afirmar que "de todos los conceptos utilizados en el conjunto de los modelos que apuntan a representar el universo, el 'tiempo' es sin duda el que ha sufrido más transformaciones a lo largo de nuestro siglo". Aludía al siglo XX. Cabe pensar que lo seguirá siendo en el que ya estamos y, de "existir tiempo", en todos los que traerá consigo el tercer milenio.

Racional y emocionalmente no queda otra opción, al menos si como reivindican las nuevas lecturas sobre el valor del tiempo y sus medidas, no importa tanto la cantidad de tiempo disponible como la calidad de lo que en él se hace, asociada a su programación, distribución y usos. De este cambio de mirada participan los descubrimientos que sustentan la teoria de la relatividad, propiciando el abandono de las tesis que alimentaron la idea de que habia un tiempo absoluto único; frente a ellas, como ha argumentado Stephen Hawking $(1989,221)$, cada observador elabora sus propias mediciones del tiempo, registradas por el reloj del que es portador: "relojes correspondientes a diferentes observadores no coincidirian necesariamente. De este modo, el tiempo se convirtió en un concepto más personal, relativo al observador que lo medía". El tiempo imaginario, al que se remite Hawking, no tiene límites ni orientaciones, negando las propiedades que le suele atribuir el sentido común: dirección, irreversibilidad, duración.

La "flecha del tiempo", una figura antigua a la que recurrió en 1927 el astrónomo británico Arthur Stanley Eddington para representar el tiempo como un fenómeno unidireccional, que va del pasado al futuro en una sola trayectoria, chocará frontalmente -en la Física moderna- con las hipótesis que defienden la irreversibilidad del tiempo, del que dirán que tal vez no sea más que una ilusión, un fenómeno psicológico y subjetivo, una apariencia engañosa. Lo transmite con una inequívoca radicalidad Simonetta Tabboni (2006, 29), cuando afirma que "el tiempo en el cual nosotros vivimos no tiene verdaderamente nada de objetivo: es un elemento cultural fundamental que, como tal, varia de una sociedad a otra y responde en sus formas fundamentales a funciones, experiencias y condiciones cambiantes". De acuerdo con esta representación de la temporalidad, coincidimos con Aguinaga y Comas (1997, 218) en la necesidad de evitar caer en dualizaciones poco sensatas sobre el "tiempo vivido" y el "tiempo real", con las que se tiende a silenciar "que el tiempo es, en sí mismo, una construcción social y que por tanto sólo podemos analizar las diferentes temporalidades desde la globalidad del tiempo, es decir, la singularidad de las temporalidades no refleja tiempos distintos sino usos distintos, cada uno de los cuales funciona como un significante del mismo tiempo".

El énfasis en la inter-subjetividad del tiempo, apelando a sus atributos fenomenológicos, psicológicos y sociales, tiene en la sensación de "duración" uno de sus principales avales, al variar según las circunstancias, de persona a persona, en función de la ocupación y de las preocupaciones (Hargreaves, 1996). Las sensaciones cambian en función de aquello en lo qué pensemos y de cómo lo hagamos; los científicos que las indagan en el reloj biológico todavía no están muy seguros de cómo el cerebro sigue el paso del tiempo, en sus intervalos cortos y largos, en la dilatación o condensación de sus frecuencias altas, medias y bajas. Hay teorias que sostienen que el cerebro posee un grupo de células especializadas en agrupar secuencias de tiempo; otras postulan que la tarea depende de un conjunto de procesos neuronales que actúan como un verdadero cronómetro interno. Las percepciones, más o menos gratas, que se suscitan en los tiempos de ocio, participan plenamente de estas interpretaciones.

Sea como sea, la supuesta objetividad de los tiempos del reloj mecánico, de los horarios y calendarios, que parecen ordenar de forma "natural" nuestras sincronías en el tiempo, "esconden en realidad siglos de debate ideológico y conflicto político" (Durán y Rogero, 2009, 11), producto de posicionamientos subjetivos, reveladores del poder ejercido por las religiones, los Estados y los sistemas productivos. A su influencia debemos la división "orgánica" y "dinámica" de nuestro quehacer social en distintos ciclos temporales (diario, semanal, anual, vital), moldeados y labrados históricamente, adaptados y adoptados universalmente a pesar de sus incoherencias. La semana -un intervalo artificial creado por los hombres-, y a pesar de ello convertida en

ARBOR Vol. 188754 marzo-abril [2012] 301-313 ISSN: 0210-1963

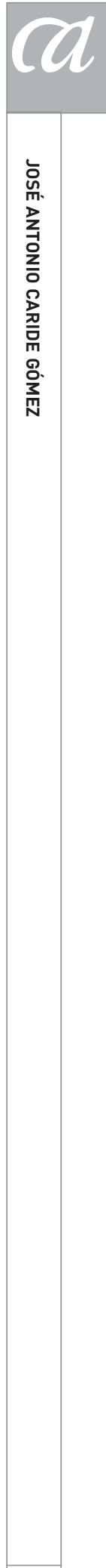


una de las medidas más comunes del tiempo y de la vida diaria, es uno de sus más claros exponentes (Rybczynski, 1992). Los ritos y creencias que Mircea Eliade $(2000,56)$ agrupaba bajo el título la "Regeneración del tiempo" en su excelente ensayo sobre El mito del eterno retorno, ya despejaba algunas dudas sobre la infinita variedad de las formas temporales que en ellos se encarnan, morfológica y diacrónicamente, evitando caer en el engaño de su posibilidad de "encuadrarlos en un sistema coherente y unitario".

El fondo de la cuestión reside en que la determinación sociocultural del tiempo no solo induce a las diferentes sociedades y culturas a acomodarse a concepciones dispares -o uniformes- del tiempo, "sino que cada una de tales concepciones se vive como real por aquellos que forman parte de dicha cultura" (Aguinaga y Comas, 1997, 215216) y de tales sociedades. Los modos mismos de contar el tiempo, de percibirlo, de concebirlo y expresarlo son culturales y, por tanto, históricos (Capella, 2000).

Cada época y cada cultura, al mostrar la pluralidad de los tiempos que modulan sus realidades, son un testimonio fehaciente de la compleja arquitectura temporal a la que nos debemos. En ella, compartiendo los argumentos de Ramos Torre (1992, XI-XII), la "multiplicidad del tiempo" constituye una "hipótesis irrenunciable", que subraya la caracterización de aquél como "un concepto que generaliza, sintetiza o totaliza aspectos muy variados de la experiencia". Como tal, ejerce una constante influencia en la educación, dentro y fuera de las escuelas, en la vida familiar y en cualquier escenario susceptible de movilizar pedagógicamente la sociedad, expandiendo los horizontes temporales de las prácticas educativas: en su interior, "la realidad educadora se vertebra a partir de un sistema integrado de tiempos" (Romero, 2000, 28). En él, con ellos, el ocio y su educación deben fomentar valores, actitudes, conocimientos, competencias, habilidades, etc., que ofrezcan alternativas plausibles a los apresurados ritmos de la vida moderna y a sus continuados "robos de tiempo" (Caballo, Caride y Meira, 2011).

Como se sabe, desde el Renacimiento, la conciencia de temporalidad no ha hecho más que acelerarse, impulsando la continua liberación de las concepciones canónicas, litúrgicas y estacionales de épocas anteriores (Le Goff, 1991). La introducción de los relojes comunales en las ciudades y, más tarde, su portabilidad individualizada, contribuiría definitivamente a la estandarización de las medidas del tiempo a nivel mundial, fruto del acuerdo adoptado en 1884 por 27 países, reunidos en Washington en la Conferencia del Meridiano. La organización y coordinación de las sociedades modernas -dirá Iglesias de Ussel (2006, 57)- llegó a hacerse plenamente operativa cuando el reloj portátil comenzó a producirse en serie, convertido en piedra angular, metáfora y símbolo de la precisión y la exactitud: "sin el reloj -añade- no hubiera sido posible la ruptura del individualismo precapitalista y dar paso a la nueva sociedad de masas".

Las aportaciones de Albert Einstein, sometiendo las nociones del tiempo a una relectura físico-matemática de sus coordenadas, harán hincapié en las relaciones estructurales existentes entre tiempo y espacio, destacando en ellas la relatividad del instante. En este sentido, la distribución de actividades en los límites espacio-temporales de las últimas décadas son especialmente reveladoras de los cambios que se han producido en la llamada zonificación o colonización del tiempo (Giddens, 1994), al menos en una doble coyuntura: la geográfica, posibilitando que las personas transiten por husos horarios que rompen su ordenada adscripción a la unidireccionalidad del tiempo; la cronológica, posibilitando que en una sociedad abierta las 24 horas todos los días del año (gracias a la invención de la electricidad), el día y la noche no sean factores decisivos en la diferenciación que cabe establecer entre el tiempo de actividad y el de descanso. De ambas circunstancias se derivan aprendizajes con una notable incidencia en la vida cotidiana de la gente en todo el mundo, obligándolas a socializarse en pautas de trabajo, recreación, comunicación, cuidado, movilidad, turismo, etc., desconocidas hasta no hace mucho.

En la sociedad red, "que se yergue en la orilla de la eternidad" (Castells, 1998, 503), todo indica que podemos estar situados, por vez primera en los últimos siglos, ante la posibilidad de emanciparnos para siempre de la cultura del reloj, tan decisivo en la consolidación de las sociedades industriales y urbanas. Las nuevas tecnologías de la información, con capacidad para expandirse por todo el Planeta, han introducido un giro radical en nuestros modos de inscribir el tiempo en la experiencia humana: con él, la ruptura progresiva de los vínculos existentes entre los ritmos biológicos y sociales que articularon secularmente el ciclo vital, dará paso a las lógicas de la "simultaneidad" y 
la "atemporalidad" que definen la cultura de la virtualidad real y la realidad de lo virtual. Para Castells, el "tiempo indiferenciado" y el "tiempo atemporal" adquieren formas propias de un "tiempo social" alternativo a los tiempos naturales y sociales conocidos, que se están haciendo añicos en la era de la información. Un tiempo episódico que, según Bauman (2001), se edifica alli donde se produjo el desmoronamiento del tiempo continuo, acumulativo y direccional que cultivamos durante siglos.

Sin que obviemos otras connotaciones, las evidencias apuntan hacia la necesidad de que los derechos humanos y su proyección en el trabajo, la educación y la cultura se doten de nuevos sentidos; entre otros, los que conduzcan a repensar el protagonismo que ha de tener en nuestras sociedades el negocio (al menos, en su versión más restringida, que lo asimila al capital económico que nutren la fuerza laboral y las plusvalías de su productividad) y el ocio, concebido como una práctica individual y colectiva cada vez más relevante para lo que hemos dado en llamar -en la versión más amplia del término- capital social, exponente de los logros asociados al bienestar de la ciudadanía y a la mejora expansiva de nuestras convivencias. No será fácil, ya que, como interpretan Lewis y Weigert (1992), la inserción de los individuos en las diferentes tipologías de los tiempos sociales -organizativo, institucional, interactivo y personal- presenta una gran complejidad, dificultando la sincronización de los actos y de los actores, en las biografías de los sujetos y en su vida en común. Los conflictos en el tiempo social, concluyen, tienen "ramificaciones que alcanzan a toda estructura de la sociedad, afectando profundamente a la calidad de vida de sus miembros" (Lewis y Weigert, 1992, 127). En este contexto, como ha señalado Cuenca $(2004,72)$, el disfrute y el ejercicio del ocio, sea a nivel personal o comunitario, no depende tan sólo del hecho de disponer de tiempo y de recursos, sino, "y de un modo especial, de la percepción y actitud que se tiene sobre el mismo"; en ambas, añade, el papel de la educación es determinante.

\section{UN BIEN INMATERIAL ESCASO: LOS "TIEMPOS DE OCIO" COMO NECESIDAD Y DERECHO CÍVICO}

La instantaneidad -e inmediatez- en el acceso a casi todo lo que sucede en la sociedad red, abocándonos a ir depri- sa, unida al aparente desdibujamiento de las coordenadas temporales convencionales en los telares del ciberespacio, de la cultura planetaria y del mercado global, refuerzan la percepción del tiempo como uno de los bienes más escasos de cuantos poseemos, a cuya adecuada administración -sin que se caiga en una obsesiva programación- se supedita una parte apreciable de la felicidad de las personas (Cebrián, 1988). Lo ilustra, de otro modo, M. ${ }^{a}$ Ángeles Durán (2007) al recordar los impactos psicológicos, económicos, sociales, políticos..., públicos y privados, que genera el tiempo en los diversos grupos sociales y a lo largo del ciclo vital, en lo que nos iguala y en lo que nos distingue. Un tiempo del que, aún padeciendo su falta, nunca tuvimos, como en nuestros días, "ciclos vitales tan largos y con tantas probabilidades de recorrerlos enteros. Solo por eso, por la cantidad de tiempo añadido a nuestra disposición, hay que inventar nuevas formas de usarlo fructiferamente y disfrutarlo" (Durán, 2007, 281).

Con todo, ni en el manejo de las cantidades de tiempo disponibles, ni en sus "aplicaciones", el disfrute de una vida mejor es una cuestión sencilla. En primer término, porque ambas cosas tienen significados distintos para cada persona; en segundo lugar, porque aún siendo abundantes las tentativas orientadas a racionalizar el tiempo (planificando, administrando, conciliando, etc.) con criterios saludables, nada asegura su logro. El "yo saturado" (Gergen, 1997), en una sociedad que nos ha obligado a relacionarnos con un número mucho mayor de individuos e instituciones que en cualquier época pasada, derriba los mitos que desde la sabiduria popular hasta los más tecnológicos sistemas de autoayuda han ido edificando secularmente ("para todo hay tiempo", "a quien madruga, Dios le ayuda", "no dejes para mañana lo que puedas hacer hoy", "a mal tiempo, buena cara", "el tiempo es oro", "reserve tiempo para oír sus emociones", etc.). Como ha advertido San Salvador (2000), los problemas que han de afrontarse para garantizar el derecho al ocio de todos los ciudadanos, son demasiado complejos como para ser resueltos con soluciones simples. Porque, aunque la precise, la imaginación no basta para entender ni resolver las incertidumbres que envuelven al ocio en la sociedad red, cada vez más desafiado por la tensión que provocan, en su interior, dos tendencias contrapuestas: de un lado, la que aspira a la emancipación de la sociedad; de otro, la que incrementa sus dependencias. Para San Salvador (2000, 336-337), las garantías han de buscarse en la adopción de

ARBOR Vol. 188754 marzo-abril [2012] 301-313 ISSN: 0210-1963

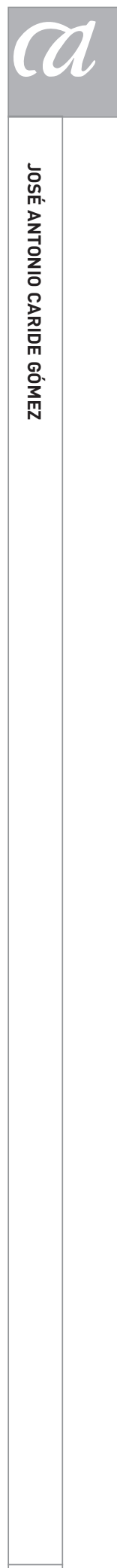

305 
un "modelo relacional de intervención política en los ámbitos del ocio", que integre "mejor los diversos elementos que se manifiestan actualmente en abierta contradicción", con estrategias flexibles e innovadoras, poliédricas y cotidianas, en lo global y en lo local.

En cierto modo, la fragmentación del tiempo -que contraría la invitación conceptual a percibirlo en sus hechuras cíclicas y policrónicas- es la que ha creado la necesidad de asociar sus cantidades a indicadores de calidad, su estricta medida a su elástica mediación. Según Poelmans (2005, XIII), dar respuesta a esta necesidad "es mucho más que llevar una buena agenda y organizar nuestros horarios... está estrechamente ligado con el modo en que gobernamos nuestras vidas, que es fruto del sentido que le demos". Este tiempo de calidad -al que está convocado explícitamente el factor ocio- es también, en último término, un ingrediente básico en la búsqueda de la felicidad personal. Aunque, como sucede en tantas otras realidades de la vida cotidiana, la relación entre la disponibilidad de ocios, el bienestar y la felicidad nunca esté garantizada, dada la importancia que en tal relación tienen variables como el empleo y su calidad, la vida familiar y social, la salud, la formación recibida, los valores cívicos, los recursos materiales y económicos, etc. En todo caso, si tener más tiempo no es una causa directa de la felicidad, carecer de él o luchar contra él (en situaciones de estrés o de encierro, de exclusión o pobreza, en desempleo, padeciendo enfermedades, etc.), acarrea la infelicidad y la desventura de mucha gente.

Nos referimos al tiempo como un bien inmaterial, que ni se toca ni se ve ni se oye, cuya reconversión en un "tiempo de ocio" comienza por desearse que sea "libre" (o, cuando menos, no impuesto), aunque este requisito no baste, máxime cuando es frecuente percibir el tiempo - por las presiones que opera sobre la voluntad de las personas- como un "enemigo de la libertad" (Hargreaves, 1996, 119), y la libertad como "un asunto demasiado serio como para convertirlo en criterio de delimitación del ocio" (Durán, 2007, 244). Además, debe procurar que sus potencialidades contribuyan a un mayor y mejor desarrollo humano, brindando a cada persona la oportunidad de ser ella misma (autorrealización), individual y socialmente: un "ocio humanista" (Cuenca, 2003), que al agrandar los derechos de los sujetos los hace partícipes de experiencias valiosas en diversos ámbitos de su cotidianeidad, activando elementos de índole física, intelectual, social, emocional, artística, etc. Que esto suceda, coincidimos con Joseph Leif (1992), dependerá de cómo se perciba y viva el tiempo, en tanto que un ejercicio efectivo de la libertad; esto es, de una verdadera capacidad de las personas para decidir autónomamente sobre sus vidas, de modo tal -dirá Leifque a la disposición del tiempo para uno mismo se añada la disponibilidad de un tiempo para/con los demás, como una exigencia inherente a cualquier proceso de socialización que sea estimable. Como un tiempo no solo libre, sino liberado de coacciones (en el trabajo, las rutinas diarias, etc.), dejará de ser un tiempo secundario para tener valor en sus concepciones y en sus significados.

El papel estructurante que Ulrich Mückenberger (2007) atribuye al tiempo en los nuevos procesos de transformación social, que suponen tener "tiempo propio" o aspirar a un "bienestar de tiempo", solo puede hacerse efectivo si aseguran a los ciudadanos y ciudadanas -dadas las desigualdades asociadas al género en las disponibilidades de tiempo (Prieto, 2007)- un máximo posible de oportunidades individuales y colectivas en su "gestión" del tiempo; esto es, el derecho a poder disponer por sí mismo "de las condiciones temporales de su cotidianeidad $y$, a partir de su propio significado, poder compaginar mutuamente la vida propia, la familia, las relaciones entre géneros y entre generaciones, el empleo y la vida pública" (Mückenberger, 2007, 271).

Desde los años ochenta del pasado siglo, hasta la crisis económica y social que experimentamos en los inicios del nuevo milenio, existían bastantes indicios acerca de cómo "el tiempo de libre disposición" podria favorecer una mayor equidad en las oportunidades formativas y culturales de la ciudadanía, acordes no sólo con los principios que han venido inspirando los procesos de democratización y democracia cultural, sino también con la caracterización del ocio como un derecho básico, de los conceptuados como de tercera generación (Caride, 2009). El interés creciente por analizar la relación existente entre el supuesto incremento del "tiempo libre" en determinados sectores de la población (los jóvenes, las personas mayores, etc.) y su participación activa en la vida pública y en la iniciativa sociocultural, en el marco de los programas nacionales e internacionales de investigación empirica en el uso del tiempo (Durán y Rogero, 2009), es un buen ejemplo de lo que decimos. 
Entonces, y mucho más ahora, lo que se observaba como un factor potencial de emancipación y equidad se ha ido transformando en un terreno proclive a la coexistencia de dos realidades con itinerarios dispares: de un lado, la que muestra el desarrollo exponencial de las industrias del ocio y de los parques temáticos, del turismo, del entretenimiento y la evasión lúdica, de la virtualización recreativas a la que dan lugar las redes sociales, o de la expansión incesante de los medios audiovisuales..., hasta el punto de haber convertido al ocio en uno de los sectores económicos más importantes en la generación de actividad económica y empleo (Vogel, 2004); de otro, el que pone de relieve como se incrementan, en parecidas magnitudes, las privaciones causadas por la pobreza, el desempleo, la privatización de los servicios o la manipulación interesada de los recursos y sus contenidos.

Con demasiada frecuencia es el abuso del trabajo lo que no permite traducir la capacidad adquisitiva en actividades de ocio, o en el predominio en éstas de las que tienen un carácter pasivo. Como exponen Paramio y Zofío (2007, 104), "unos, los profesionales postmodernos no tienen suficiente tiempo para disfrutar de todo lo que tienen (incluso para consumir es necesario tener tiempo), mientras que los trabajadores precarios no pueden trabajar todo lo que

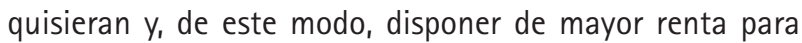
poder acceder a las mayores cuotas de consumo que exige el ocio actual". De esta forma, siendo verdad que la mayor o menor solvencia económica ensancha o restringe el acceso a las actividades de ocio, también lo es que en nuestras sociedades existen serias dificultades para conciliar la calidad de vida con el nivel de vida, en una u otra dirección.

De nuevo, casi sin pretenderlo, la educación ha de asumir el reto que supone mediar entre ambas realidades, que no es otro que el de contribuir mediante sus prácticas a la formación integral de personas que sean conscientes, críticas y responsables, libres y autónomas, en una sociedad transformada que reconozca y valore en todas sus dimensiones la textura humana. Una sociedad que en su mirada al presente sea capaz de construir futuros en los que las actividades recreativas, lúdicas o festivas sean algo más que simples "pasatiempos" que interfieren la vida práctica o que se contraponen al trabajo, abandonando "la visión unilateral que define al ser humano por la racionalidad (homo sapiens), la técnica (homo faber), las actividades utilitarias (homo economicus), las necesidades obligatorias (homo prosaiucus)" (Morin, 2001, 70). Una visión que ha cercenado la unidad-diversidad humana, cuya complejidad -insiste Edgar Morin- no se puede comprender disociada de todos los elementos que la constituyen, entre los que la creatividad, la fiesta, el arte, la recreación, el juego, la poética, las prácticas deportivas o el esparcimiento..., también muestran al ser humano en su naturaleza misma, en su más completa identidad y entidad cósmica. En ella, cualquier tiempo y todos los tiempos educan. Porque, más allá de ser tiempos de recreación y diversión, lo son de reflexión y de conocimiento del mundo, de los demás y de uno mismo.

\section{UN TIEMPO APRENDIDO, DESDE LA INFANCIA HASTA LA VEJEZ}

Los aprendizajes acerca del tiempo, así como de sus significados en y para la vida cotidiana de las personas, forman parte de un proceso que tiene en los pasajes por la infancia, y de ésta a la adolescencia, algunas de sus secuencias más decisivas. Siendo aprendizajes que no concluyen nunca, al prolongarse sus enseñanzas en otras etapas vitales, desde la juventud hasta la vejez, ponen de manifiesto la importancia de la "variable" tiempo en el desarrollo evolutivo de los sujetos, así como su mayor o menor capacidad de adaptación a las realidades que lo contornan. En ellas, la representación social del tiempo -en la que prevalece su caracterización como una experiencia construida cultural e históricamente, frente a su mera consideración como un fenómeno natural o cronológico- desempeña un papel clave: un soporte fundamental de la personalidad individual y de las interacciones sociales, que se modifica con la edad y las vivencias de cada sujeto. Como señalan Bárcena y Mélich (2000, 153-154),

el aprendizaje es una experiencia que tiene que ver con el tiempo: pues se necesita tiempo para aprender. Se necesita contar con el tiempo suficiente y también poder contar, es decir, narrar, ese tiempo ganado del aprender. El tiempo de aprender es un tiempo que se narra: el tiempo que corre, que cuenta y que se cuenta. Por eso el tiempo del aprender es siempre una narración del tiempo de la formación (los años del aprendizaje). Así, lo que aprendemos es el aprendizaje de una narración, tanto como la narración del tiempo invertido -quizá perdido- en el mismo aprender.

ARBOR Vol. 188754 marzo-abril [2012] 301-313 ISSN: 0210-1963

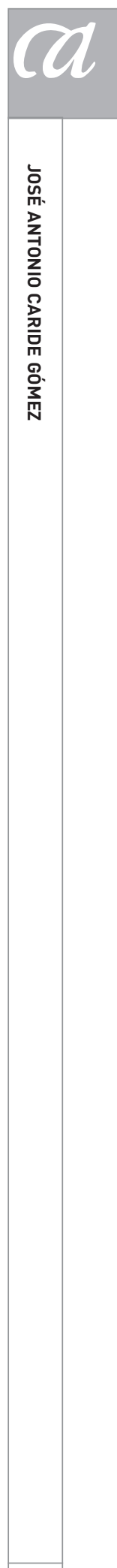

307 
En su afán por estudiar el desarrollo de las nociones temporales en la infancia, vinculadas a la explicación de la construcción de la realidad en esta etapa, Jean Piaget articuló -desde los últimos años treinta del pasado siglouna de las primeras teorias globales sobre la evolución del concepto de tiempo en los seres humanos, en buena medida sintetizada en su obra Le développment de la notion de temps chez l'enfant (Piaget, 1946), contemplando tres estadios: el del "tiempo vivido" (en el que tienen cabida las experiencias personales y directas de carácter vital); el del "tiempo percibido" (donde se sitúan las experiencias externas, de carácter social, en las que adquieren sentido la duración, las interacciones o las relaciones espacio-temporales); y el del "tiempo concebido" (de perfil histórico, desligado de referencias concretas, en el que van ganando protagonismo las categorías temporales y las experiencias mentales).

Las aportaciones de Piaget y su escuela, tratando de validar sus teorías o en discrepancia con ellas, tendrian continuidad en el quehacer intelectual y académico de una importante nómina de autores (Fraisse, Jahoda, Hannoun, Calvani, Reale, Egan, Richterman, Friedman, Smith, Montagero, Stein y Glenn, etc.). Con ellos deben mencionarse quienes se vienen ocupando de la Didáctica de la Historia $y_{1}$ en general, de las Ciencias Sociales, en diferentes etapas del sistema escolar, cuyas lecturas del tiempo -como señalan Pagès y Santisteban (2010)- requieren una mayor interdisciplinariedad, incluyendo las Ciencias de la Vida y de la Salud, en las que merecen destacarse las contribuciones realizadas por la Cronopsicobiología en los últimos años. Un tiempo que cree y recree la historia, permitiendo "volver a aprender a sentir el tiempo... en un momento en el que todo conspira para hacernos creer que la historia ha terminado y que el mundo es un espectáculo en el que se escenifica dicho fin" (Augé, 2003, 53). Un paisaje que presenta la humanidad en ruinas, cuando, tal vez, lo único que sucede es que está en obras.

Sin que nos detengamos en el cometido que cabe atribuirle a las enseñanzas que han de aportar el conjunto de los saberes en la adquisición de las nociones temporales -con sus respectivas utilidades/aplicaciones en la vida de cada persona y en la vida en común- todo indica que el aprendizaje del tiempo le cuesta a cada persona varios años, como uno de "los símbolos que los hombres pueden $y$, a partir de cierto grado de desarrollo de la sociedad, deben aprender como medio de orientación" (Elias, 1989, 30 ). No es un dato biológico innato, que viene dado por la naturaleza humana, ni un dato metafísico (que forme parte de un a priori imaginario), sino un dato social a desarrollar, "que se implanta en la conciencia con tanta mayor fuerza y profundidad, cuando las sociedades se hacen más complejas y diferenciadas" (Elias, 1989: 117).

Históricamente, las familias y las escuelas, junto con las iglesias, han sido los principales arquitectos en la construcción social del tiempo infantil (Escolano, 2000); unas y otras, muy condicionadas por la división social del trabajo, $y$, sobre todo en las últimas décadas, por las disciplinadas programaciones que hacen los medios masivos de comunicación social para sus cautivas audiencias. Aunque todas han suavizado algunas de sus formalidades, adaptando o difiriendo sus ritmos con los avances tecnológicos (entre ellos la grabación de lo que se hace "en directo", llevando al futuro lo que ya es pasado), la noción de límite está siempre presente: la presión y la rapidez siguen siendo dos de las cadenas con las que se aprisiona el tiempo y sus aprendizajes. Como exponen Hunt y Haint $(2011,197)$, la infancia -diríamos que también en los jóvenes y adultosestá cada vez más sometida a programas intensos: "los padres presionan. Los maestros insisten. Los instructores exigen. Y los niños acatan como pueden".

El supuesto de que "más es mejor", al que exhortan muchas instituciones educativas y sociales, no se compadece con la efectividad del tiempo presente ni con lo que puede esperarse de cada sujeto en las relaciones que vinculan su formación con el tiempo (Gimeno, 2008). Al igual que no se enseña siempre que se educa, tampoco se aprende siempre que se enseña, ya sea en la escuela o en otros escenarios -mal Ilamados "informales", "no formales" o "extraescolares"-, en los que la subordinación a la regulación del instituido prevalece sobre cualquier otro criterio intrínseco o extrínseco: motivación, autonomía, contextualización, participación, etc.

Aunque no se desee, en estas circunstancias, el tiempo acaba convertido en un adversario en el que los padres y las escuelas comparten la ofensiva, a la que también se suma la sociedad cibernética y telemática alentando actitudes y conductas desconcertantes, por eximentes de cualquier transgresión, asociadas -como ha llegado a constarse en una muestra de estudiantes universita- 
rios (Martín, Muñoz, Del Dujo y Sánchez, 2011, 14)- a percepciones espacio-temporales que están modificando "sensiblemente los tiempos y espacios tradicionales de desarrollo personal y de interacción social". Las experiencias de ocio, su inscripción en los nuevos tiempos sociales y los riesgos que comportan en una sociedad espacio-temporal transformada, están siendo objeto de un profundo debate intelectual y social, del que han sido un claro exponente las últimas ediciones del Foro de Investigación, Pensamiento y Reflexión en torno al fenómeno del Ocio, promovidas en el seno del Instituto de Estudios de Ocio de la Universidad de Deusto (véanse, entre otros: Cuenca y Aguilar, 2009; Lazcano y Doistua, 2010).

Las "buenas prácticas" (ocio activo, sustancial, creativo, serio, autotélico, digno, experiencial, etc.) todavía van de la mano de los "contratiempos" que también el ocio evoca en nuestras sociedades, confundiéndolo con ociosidad, banalidad, consumismo, vagancia, pereza, indolencia, etc. Mantener el anclaje perceptivo en estas últimas, cuando -como explica Lasén $(2000,170)$ - el "ocio adquiere un valor tácito en la conquista del saber y en el sentido dado a la existencia", permitiendo la creación y recreación de nuevos vínculos sociales, gracias a la densidad e intensidad humana que está ausente en otras situaciones, ya no es ignorancia o desdén, sino simple ceguera ante lo que el mundo y sus tiempos están cambiando.

Sin duda, la educación fluye e influye en el tiempo que construimos y nos construye como personas. Lo hace en la biografía de cada individuo, del que proclama su autonomía, aunque -de forma simultánea- va dejando etiquetas en su condición de ciudadano o ciudadana, recordándole que su condición de sujeto social le exige acomodar su vida particular a la vida en común, llena de exigencias temporales externas $y$, mucho más de lo que quisiera, impuestas, como sucede, por ejemplo, con la puntualidad y el orden. Como recuerda Gimeno (2008: 48), además del "poder regulador que la ordenación del tiempo tiene sobre todos los individuos, marcando las pautas organizativas de sus vidas, dicho orden estructura las relaciones, dependencias y jerarquías entre ellos; es decir, poniendo a cada uno en su lugar". Que siga siendo así no debiera suponer que pueda o deba hacerlo ad infinitum, cuando en un tiempo de cambios algunas de las principales innovaciones vienen dadas por las transformaciones que afectan a los modos de relacionarnos en el tiempo.

\section{EdUCAR EN UN OCIO LIBERADOR, QUE AMPLí LOS HORIZONTES DEL DESARROLLO HUMANO}

Junto con otras circunstancias que afectan a la salud, la formación, el trabajo o el contexto socioeconómico, los tiempos de "ocio", por su "cantidad y/o calidad", son un factor decisivo en cualquier aproximación que se haga desde el "ser del tiempo" a los "tiempos de ser" personas y sociedad (Reis, 1994). De ahí que, como un tiempo de opciones (siempre, en mayor o menor medida, condicionadas, por mucho que se pretendan libres), educar poniendo en valor la importancia del ocio para el bienestar de las personas, forma parte de las tareas pedagógica y socialmente provechosas. Lo expresaba en su Elogio de la ociosidad Bertrand Russell (2000) al significar que el sabio empleo del tiempo libre, que supone abrir la vida a la posibilidad de no verse privados de muchas de las mejores cosas, es un producto de la educación y de la civilización. Lo afirma hace años Racionero $(1983,149)$, al reconocer el "carácter sinergético" de la educación en la "sociedad del ocio", considerando que el disfrute de éste "es un arte que puede enseñarse". Un ocio con dignidad, que contribuya "a una ciudadanía completa y a una completa humanidad", en la que el derecho al ocio se remite a valores que han de ponerse en práctica "por medio de una legislación coherente con ellos y de una educación que los inculque, explique y matice" (Racionero, 1983, 148). La educación -añadiríaque sea entendida como un pilar estratégico fundamental para la transición hacia una sociedad en la que el ocio sea uno de los vectores principales de un cambio de rumbo civilizatorio.

Es en la construcción de esta civilización, como un proyecto y trayecto pedagógico-social, donde el ocio y sus "tiempos" deben reivindicar sus potenciales capacidades de aprendizaje: en los modos de ser, de hacer, de saber y convivir, como los pilares básicos de la educación del futuro (Delors, 1996). Y deben hacerlo para que ámbitos nuevos como los que apelan a la demora, la dilación, la espera o la falta de una gratificación instantánea, no sean estigmas de inferioridad; en los que el tiempo no sea un ladrón, un fastidio o una faena, como sucede en la "modernidad líquida", donde "la posición de cada uno en la escala jerárquica se mide por la capacidad (o la ineptitud) para reducir o hacer desaparecer por completo el espacio de tiempo que separa el deseo de su satisfacción. [Donde] El ascenso en la jerarquía social se mide por la creciente habilidad para

ARBOR Vol. 188754 marzo-abril [2012] 301-313 ISSN: 0210-1963

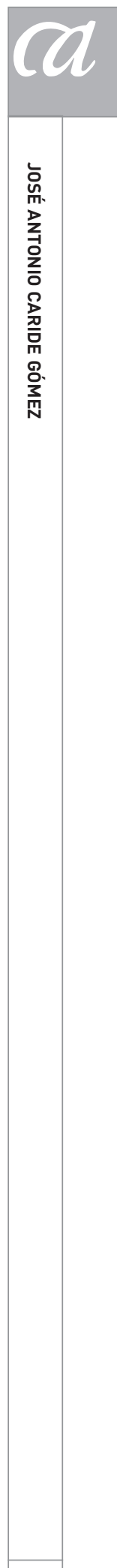

309 
obtener lo que uno quiere (sea lo que fuere eso que uno quiere) ahora, sin demora" (Bauman, 2007, 22).

Una sociedad, por tanto, distinta, en la que el concepto de "educación a lo largo de toda la vida" conduzca directamente a la noción de sociedad educadora o educativa; una sociedad que multiplique las posibilidades de aprender en cualquier escenario de la vida social y cultural, en el mundo de las asociaciones, del tejido productivo, de las familias, en las plazas y calles, en los centros civicos..., en las que el tiempo sea un activo flexible y accesible para que la vida personal y social pueda conducirse por prácticas que no quebranten la libertad humana, al menos en una doble dirección:

a) De un lado, la que posibilite guiarse por ritmos más adecuados, que no lleven a "la desaparición de ámbitos educativos clave para el desarrollo global de la persona" (Domènech, 2009: 19), creando o recuperando la filosofía del tiempo reposado. Con esta perspectiva, los elogios de la lentitud (Honoré, 2005) y de la pereza (Hodgkinson, 2005) fundamentan un movimiento que aspira a recuperar la calma para saborear la vida, luchar contra la enfermedad del trabajo y combatir el culto a la velocidad. Con la intención de conquistar el tiempo en vez de padecerlo, se trata de propiciar un tiempo interrelacionado, no fragmentado, en el que "la necesidad de mantener una gran coherencia y coordinación entre los diferentes tipos de educación es una de las premisas más importantes para poder educar a la ciudadanía" (Domènech, 2009, 59), dándole consistencia pedagógica, social y ética a los cimientos de la Pedagogía-Educación del Ocio.

Porque, no se trata de "consumir" experiencias significativas, emociones intensas o fugaces, que nutren el yo de sensaciones gratas e inmediatas, como las que propician muchos programas, equipamientos, industrias, medios o actividades pseudoeducativas en los tiempos de la noche, el fin de semana, etc. Frente e ellos, se impone la necesidad de promover procesos de maduración, más pausados y estables, sostenibles y meditados, más profundamente humanos. Las denominadas "slow cities" (ciudades lentas), enemigas del consumo excesivo y del estrés moderno, ejemplifican parte de sus principios, en los que "más", "antes" o "más rápido" no son sinónimos de "mejor". La apología del "tiempo oportuno", que para Giacomo Marramao
(2008) supone reivindicar el "kairós" con la intención de retomar el sentido de la vida en los tiempos del mundo, converge en esta expectativa, que no es otra que la que ha de permitirnos aunar dos dimensiones temporales que hoy aparecen separadas y enfrentadas, el tiempo privado y el tiempo público.

La contraposición entre los llamados ocios "negativos" (alienante, ausente, nocivo, consumista...) y "positivos" (creativo, autotélico, solidario, lúdico, ecológico, preventivo, terapéutico, festivo...), también juegan parte de sus señas de identidad en este terreno. De los primeros dirá Cuenca (1995: 56) que su direccionalidad negativa se muestra tanto "desde el punto de vista de la sociedad en la que dicha acción se manifiesta" como "desde la percepción del propio sujeto que la vivencia"; mientras que la orientación positiva del ocio es la que "habitualmente va unida a la vivencia gratificante del mismo, tanto desde el punto de vista de la persona como de la sociedad".

b) De otro, la que haciendo bueno el presagio de la llamada "civilización del ocio", a la que Joffre Dumazedier (1962) dirigió varias miradas interrogativas, sea capaz de conciliar sus propuestas con nuevos abordajes de la identidad y la diversidad de la condición humana, en sus múltiples formas y expresiones. Un ocio abierto a la resignificación de sus contribuciones a la sociedad, "buscando la posibilidad de construir nuevos conocimientos y prácticas para un aprendizaje comprometido con la transformación de la sociedad" (Elizalde, 2010). Todo ello sin que se pasen por alto las sutiles relaciones que el ocio mantiene con otras prácticas sociales, entre las que el trabajo, la religión, la política o la educación son algunos de sus principales referentes.

Aludimos a un ocio educador tanto en sus esencias como en sus evidencias, confiando a la pedagogía cívica mucho de lo que deben ser sus aportes al desarrollo de los pueblos, mejorando la autoformación y las opciones de humanización puestas al alcance de los sujetos sociales. Así lo venía reivindicando Dumazedier (1971: 43) en las últimas décadas del pasado siglo, preguntándose "¿qué cultura quiere nuestra sociedad?", "¿qué ocios desea?", transfiriendo a los colectivos sociales el desafío de buscar respuestas que posibilitaran una mayor y mejor democratización de la vida en común, esforzándose "por hacerse una representación clara de las ambigüedades del ocio y a través de ellas, de sus posibilidades múltiples". 
Ambas perspectivas convergen en la necesidad de vivir el ocio como una necesidad y un derecho educables, pedagógica y socialmente congruentes con modelos e iniciativas civicas que amplien los horizontes del desarrollo humano, que tampoco tiene porque responder a una concepción unívoca sino más bien plural. En todo caso, una educación que construye presentes y futuros habitables, con los que no se trata de demandar una nueva parcela educativa, "sino de relacionar las experiencias de ocio con los valores que sustentan nuestra vida y nuestra particular manera de entender lo que es vivir" (Cuenca, 2011, 122). Esto es, volviendo al principio, un tiempo que nos humanice en todo lo que es humano. A pesar de que hoy, en una sociedad de riesgos, pueda resultar utópico, no está mal. Como expresaron Puig y Trilla $(1987,87)$, en su justificación de los principios generales para orientar la Pedagogía del Ocio, "la utopía, sólo que en algún grado conecte con la propia realidad y que sea posible cumplir con ella alguna representación-aunque sea parcial y reducida-, es uno de los móviles más decentes de la acción educativa intencional". Será entonces cuando, aunque todas las medidas del tiempo lo desacrediten, la vida podrá ser "eterna en cinco minutos". Un hermoso cantar que Víctor Jara puso en nuestras manos abiertas, al recordar a su hija Amanda.

\section{NOTA}

1 El texto que presentamos se vincula al Proyecto de Investigación "Tiempos escolares y tiempos sociales: problemáticas especificas y alternativas pedagógico-sociales en la vida cotidiana del alumnado de Educación Secundaria Obligatoria", subvencionado mediante convocatoria pública por el Ministerio de Ciencia e Innovación en el marco del Plan $\mathrm{Na}-$ cional de I+D+i_2008-2011 (código PSI2008-04308/PSIC), con financiación de la Unión Europea a través de los fondos FEDER.

\section{REFERENCIAS BIBLIOGRÁFICAS}

Aguinaga, J. y Comas, D. (1997): Cambios de hábito en el uso del tiempo: trayectorias temporales de los jóvenes españoles, Madrid: Instituto de la Juventud.

Alfonseca, M. (2008): El tiempo y el hombre, Madrid: Universidad Autónoma de Madrid.

Augé, M. (2003): El tiempo en ruinas, Barcelona: Gedisa.

Recibido: 12 de mayo de 2011

Aceptado: 14 de julio de 2011 natalidad, narración y hospitalidad, Barcelona: Paidós.

Bauman, Z. (2001): La sociedad individualizada, Madrid: Cátedra.

Bauman, Z. (2007): Los retos de la educación en la modernidad líquida, Gedisa: Barcelona.

Boscolo, L. y Bertrando, P. (1996): Los tiempos del tiempo. Una nueva perspectiva para la consulta y la terapia sistémicas, Barcelona: Paidós.

Caballo, M. B.; Caride, J. A. y Meira, P. A. (2011): "El tiempo como contexto y pretexto educativo en la sociedad red", Educación Social. Revista de Intervención Socioeducativa, n. ${ }^{\circ} 47$, pp. 11-24.

Capella, J. R. (1993): Los ciudadanos siervos, Madrid: Trotta.

Caride, J. A. (coord.) (2009): Los derechos humanos en la educación y la cultura: del discurso político a las prácticas educativas, Rosario-Argentina: Homo Sapiens.

Castells, M. (1998): La era de la información. Economía, sociedad y cultura: la sociedad red (vol. 1), Madrid: Alianza Editorial.

Cebrián, J. L. (1998): La red: cómo cambiarán nuestras vidas los nuevos medios de comunicación, Barcelona: Círculo de Lectores. 
Cuenca, M. (1995): Temas de pedagogía del ocio, Bilbao: Universidad de Deusto.

Cuenca, M. (2003): Ocio humanista: dimensiones y manifestaciones actuales del ocio, Bilbao: Universidad de Deusto.

Cuenca, M. (2004): Pedagogía del Ocio: Modelos y Propuestas, Bilbao: Universidad de Deusto.

Cuenca, M. (2011): "Innovar y aprender disfrutando", en Cuenca, M.; Aguilar, E. y Ortega, C.: Ocio para innovar, Bilbao: Universidad de Deusto, pp. 83-140.

Cuenca, M. y Aguilar, E. (eds.) (2009): El tiempo del Ocio: transformaciones y riesgos en la sociedad apresurada, Bilbao: Universidad de Deusto.

Delors, J. (dir.) (1996): La educación encierra un tesoro: Informe a la UNESCO de la Comisión Internacional sobre la Educación para el Siglo XXI, Madrid: Santillana-Ediciones UNESCO.

Domènech, J. (2009): Elogio de la educación lenta, Barcelona: Graò.

Dumazedier, J. (1962): Vers une civilisation du loisir? París: Seuil [edición española, 1964].

Dumazedier, J. (1971): "Realidades del ocio e ideologías", en Dumazedier, J. y otros: Ocio y sociedad de clases, Barcelona: Fontanella, pp. 9-45.

Dumazedier, J. (1988): Révolution cultureIle du temps libre, 1968-1988, Paris: Méridiens Klingstieck.

Durán, M. A. (2007): El valor del tiempo: ¿cuántas horas te faltan al día?, Madrid: Espasa-Calpe.

Durán, M. A. y Rogero, J. (2009): La investigación sobre el uso del tiempo, Madrid: Centro de Investigaciones Sociológicas-CIS.

Eliade, M. (2000): El mito del eterno retorno, Madrid: Alianza-Emecé.

Elias, N. (1989): Sobre el tiempo, Madrid: Fondo de Cultura Económica.

Elizalde, R. (2010): "Resignificación del ocio: aportes para un aprendizaje transformacional", Polis: Revista Aca- démica de la Universidad Bolivariana, n. ${ }^{2}$ 25. Disponible en: http://www.revistapolis.cl/25/art25.htm. Acceso el 13/05/2011.

Escolano, A. (2000): Tiempos y espacios para la escuela: ensayos históricos, Madrid: Biblioteca Nueva.

Gabilondo, A. (2008): "Prólogo", en Alfonseca, M.: El tiempo y el hombre, Madrid: Universidad Autónoma de Madrid, pp. 11-14.

Gergen, K. J. (1997): El yo saturado. Dilemas de identidad en el mundo contemporáneo, Barcelona: Paidós.

Giannini, H. (2001): El pasar del tiempo y su medida, Santiago de Chile: Editorial Universitaria.

Giddens, A. (1994): Sociología, Madrid: Alianza.

Gimeno, J. (2008): El valor del tiempo en educación, Madrid: Morata.

Hargreaves, A. (1996): Profesorado, cultura y postmodernidad (cambian los tiempos, cambia el profesorado), Madrid: Morata.

Hawking, S. (1989): Historia del tiempo: del big bang a los agujeros negros, BarceIona: Círculo de Lectores.

Hodgkinson, T. (2005): Elogio de la pereza: el manifiesto definitivo contra la enfermedad del trabajo, Barcelona: Ediciones del Bronce.

Honoré, C. (2005): Elogio de la lentitud: un movimiento mundial desafío el culto a la velocidad, Barcelona.

Hunt, D. y Hait, P. (2011): El Tao del tiempo: cinco pasos para desacelerar y vivir plenamente el presente, Barcelona: Gedisa.

Iglesias de Ussel, J. (2006): La dimensión social del tiempo, Madrid: Real Academia de Ciencias Morales y Políticas.

Jacquard, A. (1994): Éste es el tiempo del mundo finito, Madrid: Acento Editorial.

Jünguer, E. (1998): El libro del reloj de arena, Barcelona: Tusquets.
Lasén, A. (2000): A contratiempo: un estudio de las temporalidades juveniles, Madrid: Centro de Investigaciones Sociológicas-CIS.

LeGoff, J. (1991): El orden de la memoria. El tiempo como imaginario, Barcelona: Paidós.

Lazcano, I. y Doistua, J. (2010): Espacio y experiencia de ocio: consolidación, transformación y virtualidad, Bilbao: Universidad de Deusto.

Leif, J. (1992): Tiempo libre y tiempo para uno mismo. Un reto educativo y cultural, Madrid: Narcea.

Lewis, J. D. y Weigert, A. J. (1992): "Estructura y significado del tiempo social", en Ramos Torre, R. (coord.): Tiempo y sociedad, Madrid: Centro de Investigaciones Sociológicas-CIS, pp. 89-131.

Marramao, G. (2008): Kairós. Apología del tiempo oportuno, Barcelona: Gedisa.

Martín, A. V.; Muñoz, J. M.; Del Dujo, A. G. y Sánchez, M. C. (2011): "Notas para una interpretación educativa del espacio-tiempo social en la Red", Pedagogía Social. Revista Interuniversitaria, n. 18 (tercera época), pp. 13-30.

Morin, E. (2001): Los siete saberes necesarios para la educación del futuro, Barcelona: Paidós.

Mückenberger, U. (2007): Metrónomo de la vida cotidiana: prácticas del tiempo de la ciudad en Europa, Gijón-Asturias: Ediciones Trea.

Pagès, J. y Santistebán, A. (2010): "La enseñanza y el aprendizaje del tiempo histórico en la educación primaria", Cuadernos CEDES (Campinas-Brasil), vol. 30, n. 82.

Disponible en: http://www.scielo.br/ scielo.php?pid=S0101-32622010000 $300002 \&$ script $=$ sci_arttext. Acceso el 01/05/2011.

Piaget, J. y colaboradores (1946): Le développement de la notion de temps chez I'enfant, París: PUF [edición española, 1978]. 
Paramio, J. L. y Zofío, J. L. (2007): "Calidad de vida frente a nivel de vida: la evolución del mercado laboral y de las industrias del ocio en España", Revista Española de Sociología-RES, n. ${ }^{\circ} 8$, pp. 85-114.

Poelmans, S. (2005): Tiempo de calidad. Calidad de vida, Madrid: McGraw Hill.

Prieto, C. (ed.) (2007): Trabajo, género y tiempo social, Madrid: Editorial Complutense-Editorial Hacer.

Puig, J. M. y Trilla, J. (1987): Pedagogía del Ocio, Barcelona: Laertes.

Racionero, L. (1983): Del paro al ocio, Barcelona: Anagrama.
Ramos Torre, R. (coord.): Tiempo y sociedad, Madrid: Centro de Investigaciones Sociológicas-CIS.

Reis, J. C. (1994): Tempo, historia e evassão, Campinas-SP: Papirus.

Romero, C. (2000): Conocimiento del tiempo educativo, Barcelona: Laertes.

Russell, B. (2000): Elogio de la ociosidad, Madrid: Edhasa (edición original, 1935).

Rybczynski, W. (1992): Esperando el fin de semana, Barcelona: Emecé.

San Salvador, R. (2000): Políticas de ocio: Cultura, turismo, deporte y recreación, Bilbao: Universidad de Deusto.
Santos, M. (1996): Técnica, espaço, tempo: Globalização e meio técnico-científico informacional, São Paulo: Editora Hucitec (2. ${ }^{\text {a ed.). }}$.

Savater, F. (1997): El valor de educar, Barcelona: Ariel.

Tabboni, S. (2006): Les temps sociaux, Paris: Armand Colin.

Viñao, A. (1998): Tiempos escolares, tiempos sociales. La distribución del tiempo y del trabajo en la enseñanza primaria en España (1838-1936), Barcelona: Ariel.

Vogel, H. L. (2004): La industria de la cultura y del ocio, Madrid: Fundación Autor/lberautor/SGAE. 